\title{
Comparison of thyroid stimulating hormone and triiodothyronine response to thyrotrophin releasing hormone in the assessment of thyroid status
}

\author{
C. R. SQUIRE AND T. M. D. GIMLETTE
}

From the Department of Nuclear Medicine, The Liverpool Clinic, Myrtle Street, Liverpool

SUMMARY The response to an intravenous dose of $200 \mu \mathrm{g}$ of thyrotrophin releasing hormone (TRH) has been studied by estimating, by radioimmunoassay, baseline levels followed by further estimations of thyroid stimulating hormone (TSH) 20 minutes after the injection and triiodothyronine (T3) three hours after the injection in $\mathbf{1 1 2}$ patients referred for routine thyroid assessment.

Comparison of diagnostic accuracy of the response to TRH gave similar results with both procedures but slightly better overall accuracy for the response measured by TSH assay. However, estimation of baseline T3 is a valuable test for hyperthyroidism, in contrast to baseline TSH, and combined with the estimation of T3 three hours after TRH injection provides an accurate additional test in borderline cases.

The assessment of thyroid and pituitary function by estimation of thyroid stimulating hormone (TSH) response to an intravenous dose of thyrotrophin releasing hormone (TRH) (Ormston et al., 1971) has been widely recognised as a useful procedure. The response in serum triiodothyronine (T3) level to intravenous TRH has been described (Shenkman et al., 1972); it has been less extensively employed as a routine test, and has been used mainly in the assessment of thyroid/pituitary function (Lawton et al., 1973; Faglia et al., 1975), although the value of the estimation of serum $\mathrm{T} 3$ in the diagnosis of hyperthyroidism is generally recognised. Estimation of base line serum T3 and the response to TRH seemed likely to have possible advantages over estimation of $\mathrm{TSH}$, and the response, particularly in the assessment of hyperthyroidism, has been little studied. We therefore undertook a comparison of the two procedures in routine practice.

A total of 112 patients who had been referred for assessment of thyroid status were studied; they were not receiving any relevant treatment at the time of testing and the majority had not received any in the past. Thyroid status was assessed clinically, by radioiodine and pertechnetate uptake measurement and estimation of free thyroxine index (FT41) in addition to the methods described below. The patients

Received for publication 13 December 1976 selected for the TRH procedures had generally presented somewhat equivocal findings at simple routine assessment, and the results of baseline in vitro assays were not known when the TRH procedures were carried out.

\section{Methods}

Serum TSH was estimated by radioimmunoassay, using the Phadebas TSH kit preparation, before and 20 minutes after intravenous injection of $200 \mu \mathrm{g}$ TRH.

The precision of this assay at approximately the upper limit of the normal range $(7 \mu \mathrm{U} / \mathrm{ml})$ was $\pm 1.0 \mu \mathrm{U} / \mathrm{ml}$, and an increase exceeding $2.0 \mu \mathrm{U} / \mathrm{ml}$ was taken to represent a significant response. A similar lower limit to the normal TSH response has been described (Shenkman et al., 1973: Sawin and Hershman, 1976).

Serum T3 was estimated by radioimmunoassay using the RCC Amersham kit preparation. The normal range and precision of this assay in our laboratory were described by Gimlette et al. (1975).

A preliminary study was carried out in 19 euthyroid patients to determine whether estimation of T3 two or three hours after TRH, for which previous studies (Lawton et al., 1973) had indicated similar values, would be more suitable for determining the response. The percentage increases at two and three 
hours were not significantly different: mean $37 \%$, range $11-85 \%$; and mean $36 \%$, range $18-56 \%$ respectively. The three-hour increase was more consistent (no values less than $18 \%$ ) than at two hours (three values less than $18 \%$ ). Three patients in whom small increases at two hours occurred also showed relatively small increases $(18-26 \%)$ at three hours.

In each of the 19 individuals the two- and threehour increases were similar, an increase exceeding $17 \%$ at three hours was therefore taken to represent a significant response to TRH except where the baseline T3 value was less than the lower limit of the normal range $(1.5 \mathrm{nmol} / 1)$, where an increase exceeding $0.25 \mathrm{nmol} / 1$ was taken.

\section{Results}

The results in 112 patients tested are summarised in the Table and illustrated in the Figure.

Out of 42 euthyroid patients, three gave a negative
Table Numbers of patients in different categories giving correct results when TRH response was assessed by three-hour serum triiodothyronine and 20-minute serum TSH estimations

\begin{tabular}{|c|c|c|c|c|}
\hline & & Total & $T 3$ & $T S H$ \\
\hline \multicolumn{2}{|c|}{ Euthyroid } & 35 & 33 & 32 \\
\hline & treated & 4 & 1 & 4 \\
\hline & ill & 1 & 0 & 0 \\
\hline & exoph & 1 & 0 & 0 \\
\hline & hot nodule & 1 & o & o \\
\hline \multicolumn{2}{|c|}{ Hyperthyroid } & 39 & 38 & 39 \\
\hline \multicolumn{2}{|c|}{ " treated } & 12 & 11 & 12 \\
\hline \multirow{2}{*}{\multicolumn{2}{|c|}{$\begin{array}{l}\text { Hypothyroid } \\
\text { Hypopituitary }\end{array}$}} & 13 & 11 & 12 \\
\hline & & 6 & 6 & 6 \\
\hline \multicolumn{2}{|c|}{ Total } & 112 & 100 & 105 \\
\hline
\end{tabular}

response assessed by both T3 and TSH; one patient was severely ill with extensive Crohn's disease and steatorrhoea, one was euthyroid with a 'hot' nodule, and the third was one of the four euthyroid patients in the series who had been previously treated with radioiodine for hyperthyroidism. Five patients gave

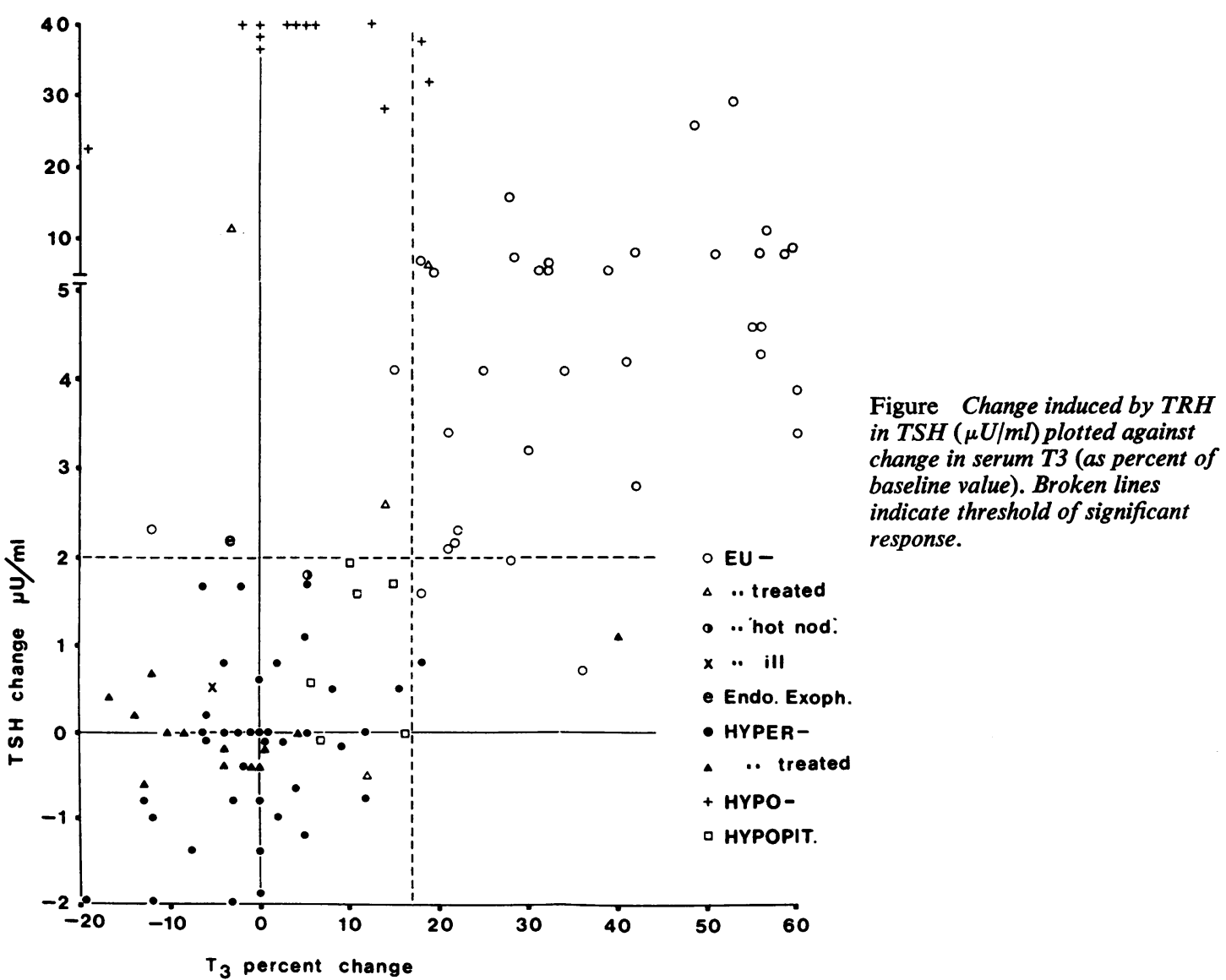


a negative response with T3 only, one was euthyroid after previous medical treatment for hyperthyroidism and one after radioiodine, one had endocrine exophthalmos (and a barely significant increase of $2 \cdot 2 \mu \mathrm{U} / \mathrm{ml}$ in TSH), and in two there was no satisfactory explanation. Three gave a negative response with TSH only, with no satisfactory explanation other than perhaps the lack of precision which occurs with this assay at the lower end of its range. The baseline T3 value was within the normal range in all the 42 euthyroid patients, and the baseline TSH was raised in two patients, one of whom had been previously treated with radioiodine.

Of the 51 hyperthyroid patients, a positive T3 response occurred in two, one previously treated with radioiodine, although this does not provide a satisfactory explanation, and a positive TSH response occurred in none. The baseline T3 estimation gave raised values in 42 of the hyperthyroid patients, but none of the nine in whom the baseline value was within the normal range showed a response to TRH.

Two hypothyroid patients showed a positive TRH response in T3 values, both had autoimmune thyroiditis with low normal baseline T3 values, elevated baseline TSH, and exaggerated TSH responses. Two other hypothyroid patients showed similar findings except for a lack of T3 response to TRH. In one patient baseline TSH values and response to TRH were within the normal range, but a low normal baseline T3 showed no significant response to $\mathrm{TRH}$, interpreted as indicating lack of thyroid reserve; this patient subsequently responded well clinically to thyroxine replacement.

The six hypopituitary patients showed no response to TRH in either TSH or T3 values.

\section{Discussion}

Comparison between the 20-minute TSH estimation and the three-hour T3 estimation in assessing TRH response gave results overall in favour of the former, and it has the further advantage, from the patient's point of view, that the procedure is concluded in a shorter time. However, in the assessment of doubtful hyperthyroidism, particularly, the $\mathrm{T} 3$ procedure has certain advantages over the TSH procedure. In the assessment of hyperthyroidism baseline TSH values per se are of no diagnostic value estimated by the relatively imprecise methods in general use. The baseline T3 estimation gave values within the normal range in all the euthyroid patients whereas all the hyperthyroid patients showed either an elevated baseline T3 or a negative response to TRH. It may be emphasised that thyroid status initially was clinically doubtful in a large proportion of the whole group.

By the method used, T3 RIA is a simple procedure and relatively more precise than TSH RIA. In doubtfully hypothyroid patients, the T3 procedure may give a useful indication of thyroid reserve or the lack of it in the presence of baseline TSH and TSH response to TRH which may be normal. We therefore conclude that the estimation of the threehour T3 response to TRH is a useful procedure which offers a satisfactory and economical addition and, in some circumstances, an alternative to the conventional TSH procedure, particularly in the assessment of doubtful hyperthyroidism.

\section{References}

Faglia, G., Ferrari, C., Paracchi, A., Spada, A., and Beck-Peccoz, P. (1975). Triiodothyronine response to thyrotrophin releasing hormone in patients with hypothalamic-pituitary disorders. Clinical Endocrinology, 4, 585-590.

Gimlette, T. M. D., Piffanelli, A., Squire, C. R., and Brocchi, A. (1975). A comparison of in vitro methods in the assessment of thyroid status. Journal of Nuclear Biology and Medicine, 19, 155-161.

Lawton, N. F., Ellis, S. M., and Sufi, S. (1973). The triiodothyronine and thyroxine response to thyrotrophin releasing hormone in the assessment of the pituitary-thyroid axis. Clinical Endocrinology, 2, 57-63.

Ormston, B. J., Garry, R., Cryer, R. J., Besser, G. M., and Hall, R. (1971). Thyrotrophin-releasing hormone as a thyroid function test. Lancet, 2, 10-14.

Sawin, C. T. and Hershinan, J. M. (1976). The TSH response to thyrotrophin-releasing hormone (TRH) in young adult men: intra-individual variation and relation to basal serum TSH and thyroid hormones. Journal of Clinical Endocrinology and Metabolism, 42, 809-816.

Shenkman, L., Mitsuma, T., and Hollander, C. S. (1973). Methods for detection of incipient primary hypothyroidism. A comparative study. Journal of Clinical Endocrinology and Metabolism, 36, 1074-1078.

Shenkman, L., Mitsuma, T., Suphavai, A., and Hollander, C. S. (1972). Triiodothyronine and thyroid-stimulating hormone response to thyrotrophin-releasing hormone. Lancet, 1, 111-113. 